\title{
The effect of Growth Hormone replacement therapy on Lipid Metabolism in Georgian patients with Growth Hormone Deficiency
}

\author{
Nestan Bostoganashvili, $M D$ \\ Ivane Javakhishvili Tbilisi State university (Tbilisi, Georgia) \\ Elene Giorgadze MD, PhD \\ Ivane Javakhishvili Tbilisi State university (Tbilisi, Georgia) \\ National Institute of Endocrinology, (Tbilisi, Georgia) \\ Shota Janjgava MD, PhD \\ Marine Lomidze MD, PhD \\ National Institute of Endocrinology, (Tbilisi, Georgia)
}

doi: 10.19044/esj.2017.v13n27p19 URL:http://dx.doi.org/10.19044/esj.2017.v13n27p19

\begin{abstract}
Introduction: Recently, Growth hormone deficiency (GHD) has become one of the reasons of significant metabolic and psychological morbidity in children and adults. The aim of our study was to find out the impact of GH replacement therapy on lipid profile in Georgian patients with GHD, which was caused by surgical resection. Design: Double Blind placebo controlled study for 12 months and an open study for another 12 months. Patients and Methods: 20 Georgian adults, aged $40.75 \pm 2.2$ years (mean \pm SE, range 20.5-60), with adult onset GH deficiency were enrolled in the study. The patients were selected from the basis of National Institute of Endocrinology. We set the inclusive and exclusive criteria to study these patients, who needed the growth hormone replacement therapy. We collected standardized information about central and peripheral hormones, metabolic activity and physical features. Results: after 12 months of GH replacement, there was no significant improvement of lipid profile in the GH deficient patients. After 24 months of the treatment, the study showed the upward trend of Triglycerides, Total cholesterol and HDL-CH, and a decrease of LDL-CH. Conclusion: The response of lipid profile to the 12 and 24 months of GH replacement in patients with GH deficiency was disappointing. The results significantly differ from the ones, provided by the European Endocrine societies. Thus, longer-term studies are required, in order to investigate accurately the whole lipid profile among our patients for the following years.
\end{abstract}


Keywords: Growth hormone deficiency, pituitary gland, lipid profile, replacement therapy, Georgia

\section{Introduction}

Recently, Growth hormone $(\mathrm{GH})$ and its physiological role in adult life have received huge attention, since the GH has an important impact on lipid and carbohydrate metabolism.

Deficiency of GH in adults causes multiple symptoms: reduced lean body mass, increased abdominal fat, abnormal carbohydrate and lipid metabolism, reduced exercise capacity, and reduced bone mineral density (Bengsson, et al., 1997.Rosel T, et al., 1997).

Untreated GHD seems to be a reason of cardiovascular risk factors such as increased visceral adiposity; premature atherosclerosis; impaired cardiac performance, elevated peripheral insulin resistance, even an abnormal cardiac structure. (Jorgensen, et al., 1989)

Hypopituitarism in adults is associated with increased vascular mortality and morbidity. (Prabhakar et al., 2006).

Cross -sectional surveys have been conducted in the several centers of the different countries. They have confirmed higher prevalence of the cardiovascular and metabolic disorders in the patients with hypopituitarism (including growth hormone deficiency), in comparison with the general population (considering the age-, sex and weight features) (Wtister et al., 1991.de Boer et al., 1994.).

Above-mentioned changes can be treated by replacement treatment with synthetic GH therapy, in addition, most of the patients also reported a significant improvement in life quality (Kellner et al.,1987. Mchorney et al., 1993. Mckenna et al., 1999. Degerblad et al., 1990).

According to the International Endocrine associations, GH treatment has the beneficial impact on body fat distribution, lipid abnormalities and flow mediated dilation, thus it seems to reduce the risk of cardiac morbidities in adults with GHD. (Lanes et al., 2008. Munzer et al., 2001). The recent blinded, randomized, placebo-controlled trials have shown a remarkable decrease in low-density lipoprotein cholesterol (LDL) levels and total cholesterol in the GHD adults, following GH replacement treatment, compared to the baseline level and the same profile of placebo-treated subjects. (Murray, et al., 2002. Salomon, et al., 1989). In the study conducted by Beshyah- Henderson, the 18 months of GH replacement therapy in hypopituitary adults produced beneficial effects on the plasma lipid profile. (Beshyah, et al., 1994).

The benefits of GH replacement therapy are not studied appropriately yet; However, it is confirmed that recombinant GH is well tolerated, with a 
low incidence of side effects and it improves most of the alterations observed in GH deficient adults (Johansson, et al., 1997. Reed, et al., 2003. Lucidi, et al., 2002)

In our study, we report the 24 months result of GH therapy on lipid metabolism in the Georgian Patients with adult onset growth hormone deficiency.

\section{Methods}

This prospective, double blind study was conducted at the National Institute of Endocrinology (Tbilisi, Georgia). The study protocol was approved by the ethical committee of the National Institute of Endocrinology, according to the declaration of Helsinki. The Inclusion Criteria were as follows:

- $\quad$ Males and females aged 18 years or over;

- Diagnosis of adult GHD for at least 6 months, or patients who have hypopituitarism resulting from surgical resection;

- $\quad$ No history of exposure to any GH within the past 12 months prior to screening;

- Adequate doses of replacement hormones (vasopressin, levothyroxine, fludrocortisone) for at least 6 months prior to screening;

- No history of Statin therapy, within the past 12 months.

Exclusion criteria:

- Patients with acute or chronic conditions or diseases that could confound results of the study.

- $\quad$ Presence of contraindications to GH treatment.

- $\quad$ Patients who have participated in the clinical studies within 6 months of screening.

- $\quad$ Patients with active malignant diseases (except the surgically removed basal cell carcinoma)

- $\quad$ Patients with a new diagnosis of pituitary adenoma within the 15 months of screening

- $\quad$ Presence of untreated adrenal insufficiency, active acromegaly in the past 4 years, or active Cushing's syndrome in the past 1,5 years

- $\quad$ Patients with type 1 diabetes mellitus or uncontrolled type 2 diabetes mellitus (glycated hemoglobin (HBA1c) of $\geq 8 \%$ )

Twenty patients (11 females and 9 males) were studied. They were recruited from the National Institute of Endocrinology. All the twenty patients had acquired the condition during their adult life, after the surgery on the pituitary gland, causing Hypopituitarism. (hypopituitarism is defined as a disorder in which the pituitary gland does not produce one or more hormones). 


\section{Study protocol}

After baseline assessments, patients were enrolled in a randomized, double blind, placebo-controlled trial of either $\mathrm{GH}$ or placebo for the 24 months period.

Patients were reviewed at 0,6 , and 12 months during the double blind, placebo-controlled study, $(n=20)$, followed by an open trial of another 12-months duration $(\mathrm{n}=10)$.

\begin{tabular}{|c|c|c|}
\hline & GH replacement & Placebo \\
\hline $\mathrm{N}$ & 10 & 10 \\
\hline $\mathrm{Sex}$ & $\mathrm{F}-8 \mathrm{M}-2$ & $\mathrm{~F}-3 \mathrm{M}-7$ \\
\hline BMI $(\mathrm{kg} / \mathrm{m} 2)$ & $28.9 \pm 2.8$ & $27.6 \pm 3.9$ \\
\hline Duration of Hypopituitarism & $2 \mathrm{yrs} \pm 3$ months & $2 \mathrm{yrs} \pm 5$ months \\
\hline
\end{tabular}

\section{Laboratorial Features}

GH deficiency was defined biochemically, based on the results of the blood GH, IGF and IGF binding protein3tests. Levels of GH were tested 7 times during 120 minutes. Serum $\mathrm{GH}$ response to insulin-induced hypoglycemia (blood glucose, $\sim 2.2 \mathrm{mmol} / \mathrm{L}$ ) was used to define $\mathrm{GH}$ deficiency.

In this study, the proposed reference intervals of the standard kit for the above-mentioned tests were as follows:

$\mathrm{GH}$

\begin{tabular}{|c|c|}
\hline Time & Normal reference \\
\hline 0, minute & $0-10 \mathrm{mIUml}$ \\
\hline $\begin{array}{c}\text { Stimulated Gh after } 15,30,45, \\
60,90,120 \text { minutes }\end{array}$ & $>10 \mathrm{mIUml}$ \\
\hline
\end{tabular}

IGF-1

\begin{tabular}{|c|c|}
\hline Age & Normal reference \\
\hline $16-24$ & 182 to $780 \mathrm{ng} / \mathrm{ml}$ \\
\hline $25-39$ & 114 to $492 \mathrm{ng} / \mathrm{ml}$ \\
\hline $40-54$ & 90 to $360 \mathrm{ng} / \mathrm{ml}$ \\
\hline$>55$ & 71 to $290 \mathrm{ng} / \mathrm{ml}$ \\
\hline
\end{tabular}

IGFbp3

\begin{tabular}{|c|c|}
\hline Age & Normal reference \\
\hline $20-35$ & $3.5-7.6 \mathrm{mcg} / \mathrm{ml}$ \\
\hline $35-40$ & $3.3-6.7 \mathrm{mcg} / \mathrm{ml}$ \\
\hline$>40$ & $3.3-6.7 \mathrm{mcg} / \mathrm{ml}$ \\
\hline
\end{tabular}


Plasma lipids were measured after $10 \mathrm{hr}$. overnight fasting period. Serum cholesterol and triglyceride levels were assayed enzymatically. High density lipoprotein (HDL) cholesterol was assayed after precipitation of other lipoproteins with dextran sulfate and magnesium. LDL cholesterol was calculated from Fried Wald's formula.

A human growth hormone, comprised of the authentic human GH sequence, was given weekly by intramuscular injection. The starting weekly dose was $0,33 \mathrm{IU} / \mathrm{kg}$ and was later adjusted according to patients' tolerance by $25 \%$ or $50 \%$ decrements, as required. The placebo consisted of freezedried sterile sodium bicarbonate.

\section{Results \\ Patients}

10 Georgian patients with Hypopituitarism received Recombinant growth hormone for 24 months, other 10 patients (as control group) did not receive the medication. The patients of the both groups had adult onset growth hormone deficiency.

The mean age of the patients was $40.75 \pm 2.2$ years. At baseline, all the patients (in treatment and control groups) had dyslipidemia. Furthermore, After the surgery on the pituitary gland adenoma, 90\% of the patients suffered other symptoms, related to GHD, such as: myalgia, arthralgia, chronic fatigue syndrome, weight gain $(6 \pm 2.4 \mathrm{~kg})$. We recommended all the patients to be physically active and to follow a healthy diet.

\section{The effects of the treatment}

We decided to control and compare the baseline values of lipid profile to the levels obtained at the $12^{\text {th }}$ and the $24^{\text {th }}$ months of the study.

Among the GH treated patients, there was an increase of mean values of LDL-CH, total cholesterol (CH) and triglycerides (TG), After 12 months of the study. Surprisingly, there was a decrease of Total CH, LDL-CH and TG, in the patients not receiving the GH. HD-Ch was elevated in the both groups. We presume, it could be result of the healthy diet and Physical activity. (Table 1)

Table $1 \mathrm{GH}$ effect on lipid profile after 12 months of the study

\begin{tabular}{|c|c|c|c|c|}
\hline \multicolumn{2}{|c}{ Treatment group } & \multicolumn{3}{c|}{ Control group } \\
\hline & Month 0 & Month 12 & Month 0 & Month 12 \\
\hline Total cholesterol & $5.44 \pm 1.1 \mathrm{mmol} / 1$ & $5.54 \pm 0.9 \mathrm{mmol} / 1$ & $4.96 \pm 1.2 \mathrm{mmol} / 1$ & $4.89 \pm 0.97 \mathrm{mmol} / 1$ \\
\hline HDL-CH & $0.8 \pm 0.25 \mathrm{mmol} / 1$ & $1 \pm 0.33 \mathrm{mmol} / 1$ & $1.2 \pm 0.98 \mathrm{mmol} / 1$ & $1.25 \pm 1.1 \mathrm{mmol} / 1$ \\
\hline LDL-CH & $3.55 \pm 1.3 \mathrm{mmol} / 1$ & $3.65 \pm 1.5 \mathrm{mmol} / 1$ & $3.1 \pm 1.12 \mathrm{mmol} / 1$ & $3.0 \pm 1.3 \mathrm{mmol} / 1$ \\
\hline Triglycerides & $2.2 \pm 0.56 \mathrm{mmol} / 1$ & $2.5 \pm 0.4 \mathrm{mmol} / 1$ & $1.5 \pm 0.9 \mathrm{mmol} / 1$ & $1.4 \pm 0.7 \mathrm{mmol} / 1$ \\
\hline
\end{tabular}


However, the Study group showed, that the total $\mathrm{CH} / \mathrm{HDL}$ and LDL/HDL cholesterol ratios were decreased. Based on this, we conc luded, that the 12-months Study period was not sufficient to determine the full impact of GH on lipid profile. Thus, it was important to observe the data in open trial study, $(\mathrm{n}=10)$ for another 12- months period;

From Baseline to 24 months of treatment, there was a significant increase in median Total cholesterol and Triglycerides in the GH treated patients (Figure 1, Table 2), $\mathrm{TG}+22.73 \%$, total $\mathrm{CH}+5.56 \%$ ). However, there was an evident improvement regarding LDL-CH and HDL-CH values, (LDL $-11.43 \%$; HDL $+50 \%$ ).

Fig.1 Levels of lipid profile at Baseline and after $12^{\text {th }}$ month and the $24^{\text {th }}$ month of the GH treatment (study group)

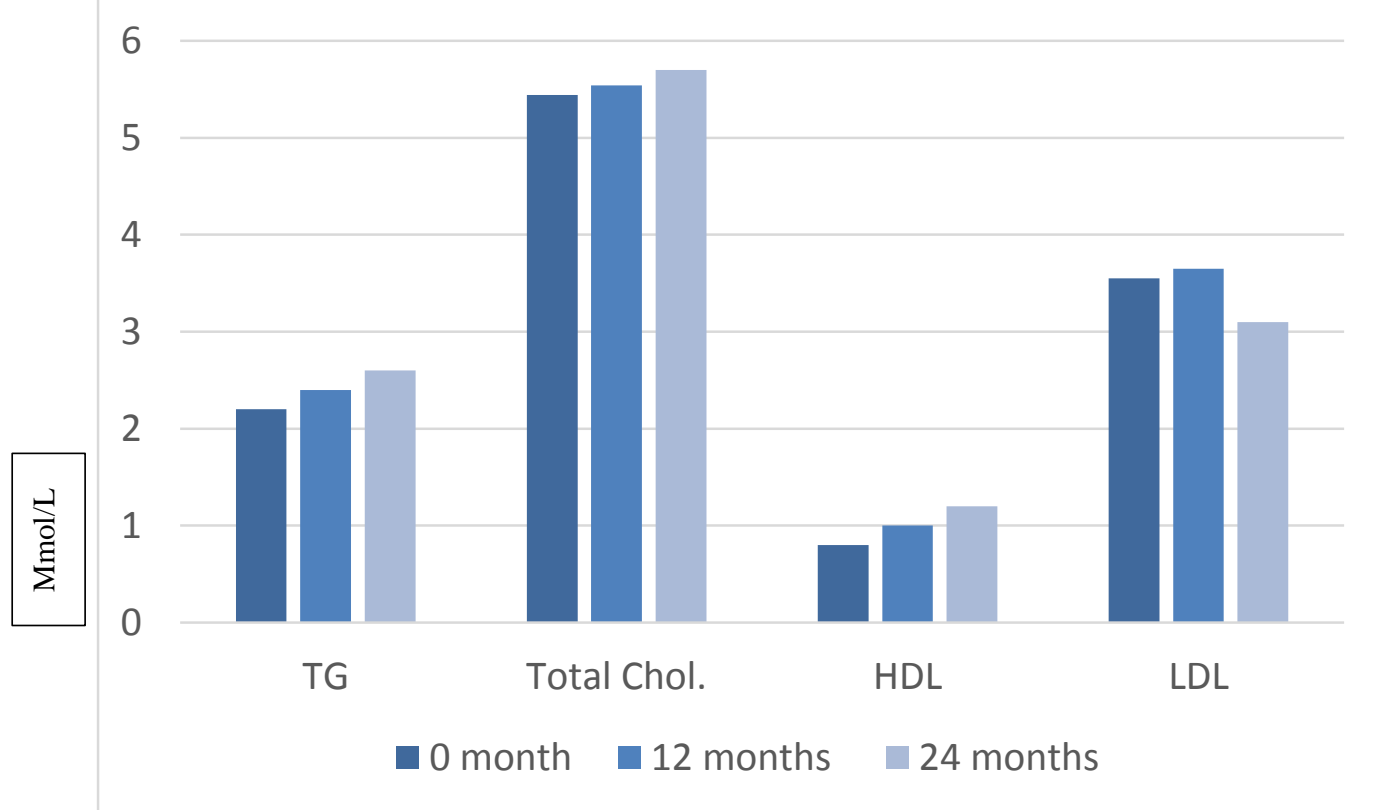

Values are the mean \pm SD.

Table 2.Percentage change in Lipid profile in GH treatment group

\begin{tabular}{|c|c|c|}
\hline Indicators & \multicolumn{2}{|c|}{ Median \% change from the baseline } \\
\hline & 12 Months & 24 Months \\
\hline Triglycerides & $+13.64 \%$ & $+22.73 \%$ \\
\hline Total Cholesterol & $+2.59 \%$ & $+5.56 \%$ \\
\hline HDL-CH & $+25 \%$ & $+50 \%$ \\
\hline LDL-CH & $+4.29 \%$ & $-11.43 \%$ \\
\hline
\end{tabular}




\section{Discussion}

In the present study, we examined both: the short and long-term effects of GH therapy on lipid metabolism in adults with $\mathrm{GH}$ deficiency. The 12-months placebo controlled period was followed by an open trial, which lasted other 12 months. In Georgia, it was the first study on GHD and its effects on lipid profile in adults. GH deficiency was defined on the basis of stimulated $\mathrm{GH}$ response less than $10 \mathrm{mU} / 1$. The most of the patients had severe GH deficiency (below $4 \mathrm{mU} / \mathrm{l}$ ). As long as, GHD seems to be one of the reasons of dyslipidemia, we found it important to study $\mathrm{GH}$ replacement effect on the plasma lipid metabolism.

Surprisingly, the results we expected were somehow different from the ones, we have received. In our study, it was obvious that the lipid profile was significantly worsened after $\mathrm{GH}$ treatment- total cholesterol, triglycerides and LDL-CH were elevated after 12 months of the study, it was only HDL-CH, which showed slight improvement. The period of another 12 months of the study was also interesting for us, since TG and total $\mathrm{CH}$ continued to elevate stably. However, LDL-CH was significantly decreased, as for HDL- $\mathrm{CH}$, it showed the best response to $\mathrm{GH}$ treatment $(+50 \%$, after 24 months of the treatment).

Obviously, the high levels of total $\mathrm{Ch}$ and $\mathrm{TG}$ are important indicators of dyslipidemia, that is why, our study confirms, that $\mathrm{GH}$ treatment can have unsatisfactory effects on lipid profile. The reason of that can be an environment, the nutritional habits, lifestyle etc.

The results of our study are not consistent with the data obtained in other studies, confirming total improvement of lipid profile after $\mathrm{GH}$ replacement therapy.

Considering possible reasons, we still find it difficult to explain the deviations in the studies of other researchers. We presume it could be the result of the different duration of the study, $\mathrm{GH}$ dose or injection frequency, preexisting lipid profile, coexisting illnesses etc. e.g. In BeshyahHendersons' study (study duration - 18 months) $\mathrm{GH}$ at a dose of $0.04 \mathrm{IU} / \mathrm{kg}$ was injected daily; (Beshyah, et al.,1994), while in our study, that lasted 24 months, GH was injected once weekly at a dose of $0,33 \mathrm{IU} / \mathrm{kg} /$ week.

However, there are couple of studies, which have shown that $\mathrm{GH}$ treatment improve the lipid profile, just partially (e.g Salomon's study demonstrated a significant reduction in total cholesterol, but not in plasma triglycerides after 6 months of GH treatment, (Salomon et al, 1989).

Does the GH treatment induce the total improvement of the lipid profile in GHD adult patients? The results of our study put this issue under doubt. 


\section{Conclusion}

The present study provides a good example, that several issues regarding the replacement therapy in the patients with hypopituitarism must be checked in different countries, on several clinical bases. We find it important to continue our study to determine whether prolonged $\mathrm{GH}$ replacement has the beneficial effect on the lipid profile or not.

\section{References:}

1. Bengtsson BA, Christiansen JS, Cuneo RC y Sacca L. 1997 Cardiovascular effects of GH. J Endocrinol 152:1-3.

2. Rosen T, Eden S, Larson G, Wilhelmsen L y Bengtsson BA.1997 Cardiovascular risk factors in adult patients with growth hormone deficiency. Acta Endocrinol (Copenh) 129(22):195-200.

3. Jorgensen JOL, Pederson SA, Thuesen L, et al. 1989 Beneficial effects of growth hormone treatment in GH-deficient adults. Lancet.1(12):1221-1225.

4. V K B Prabhakar and S M Shalet . Aetiology, diagnosis, and management of hypopituitarism in adult life. Postgrad Med J. 2006 Apr; 82(966): 259-266.

5. Kellner R. A symptom questionnaire. J Clin Psychiatry. 1987; 48(7):268-274. [PubMed]

6. McHorney CA, Ware JE, Jr, Raczek AE. The MOS36-Item ShortForm Health Survey (SF-36): II Psychometric and clinical tests of validity in measuring physical and mental health constructs. Med Care. 1993;31(3):247-263. [PubMed]

7. McKenna SP, Doward LC, Alonso J, et al. The QoL-AGHDA: an instrument for the assessment of quality of life in adults with growth hormone deficiency. Qual Life Res. 1999;8(4):373-383. [PubMed]

8. Degerblad M, Almkvist 0, Grunditz R, et al. 1990 Physical and psychological capabilities during substitution therapy with recombinant growth treatment in adults with growth hormone deficiency. Acta Endocrinol (Copenh). 123(5):185-193.

9. Wtister C, Slenczka E, Ziegler R. 1991 Erhohte Pravalenz von osteoporose und arteriosklerose bei konventionell substituierter hypophysenvorderlappenin suffizienz: bedarf einer zusatzlichen wachstumshormonsubstitution? Klin Wochenschr. 69(331):769-773.

10. deBoer H, Blok GJ, Voerman HJ, Philips M, Schouten JA. 1994 Serum lipids in growth hormone deficient men. Metabolism. 43(14):199 -203.

11. Roberto Lanes, M.D. Pediatric Endocrine Unit,Hospital de Clinicas Caracas,Caracas, Venezuela. Metabolic abnormalities in growth hormone deficiency. RAEM • 2008: 221 (45).214-220 
12. Münzer T, Harman SM, Hees P, Shapiro E, Christmas C, Bellantoni $\mathrm{MF}$, et al. Effects of $\mathrm{GH}$ and/or sex steroid administration on abdominal subcutaneous and visceral fat in healthy aged women and men. J Clin Endocrinol Metab. 2001; 86(8): 3604-3610.

13. Murray RD, Wieringat GE, Lissett CA, Darzy KH, Smethurst LE y Shalet SM. 2002

14. Low dose replacement improves the adverse lipid profile associated with the adult GH deficiency syndrome. Clin Endocrinol 56(23):525532.

15. Salomon F, Cuneo RC, Hesp R, Siinksen PH. 1989 The effects of treatment with recombinant human growth hormone on body composition and metabolism in adults with growth hormone deficiency. N Engl J Med. 321(26):1797-1803.

16. Beshyah SA, Henderson A, Niththyananthan R, Sharp P, Richmond W, Johnston DG. 1994 Metabolic abnormalities in growth hormone deficient adults II, Carbohydrate tolerance and lipid metabolism. Endocrinol Metab. 1(5):173-180.

17. Johannsson G, Mårin P, Lönn L, Ottosson M, Stenlöf K, Björntorp $\mathrm{P}$, et al. Growth hormone treatment of abdominally obese men reduces abdominal fat mass, improves glucose and lipoprotein metabolism, and reduces diastolic blood pressure. J Clin Endocrinol Metab. 1997; 82(3): 727-734. [Abstract | Full text]

18. Mary L. Reed, ${ }^{1, *}$ George R. Merriam, ${ }^{2, *}$ and Atil Y. Kargi ${ }^{3}$ Adult Growth Hormone Deficiency - Benefits, Side Effects, and Risks of Growth Hormone Replacement. Frontiers in endocrinology 2013; 4(12): 64-72

19. Lucidi P, Parlanti N, Piccioni F, Santeusanio F, De Feo P. Short-term treatment with low doses of recombinant human GH stimulates lipolysis in visceral obese men. J Clin Endocrinol Metab. 2002; 87(7): 3105-3109. 